\title{
Rhabdomyolysis following co-prescription of fusidic acid and atorvastatin
}

\author{
${ }^{1} \mathrm{~S}$ Teckchandani, ${ }^{2} \mathrm{~S}$ Robertson, ${ }^{3} \mathrm{~A}$ Almond, ${ }^{4} \mathrm{~K}$ Donaldson, ${ }^{5} \mathrm{C}$ Isles \\ ${ }^{1}$ Specialty Registrar; ${ }^{2,3}$ Associate Specialist; ${ }^{4,5}$ Consultant Physician, Renal Unit, Dumfries and Galloway Royal Infirmary, Dumfries, UK
}

\begin{abstract}
The placebo-corrected incidence of rhabdomyolysis in a systematic review of 20 statin trials was I.6/100,000 per year. It is likely to be higher than this in everyday clinical practice when statins are knowingly or inadvertently co-prescribed with drugs that interfere with their metabolism. We report a case of rhabdomyolysis causing muscle weakness and prolonging an episode of dialysisdependent acute kidney injury, which occurred when fusidic acid was co-prescribed with atorvastatin. Renal function and muscle power recovered when both drugs were withdrawn. We found four other cases of rhabdomyolysis with fusidic acid and atorvastatin and three with fusidic acid and simvastatin in the literature, a review of which suggests that the risks of rhabdomyolysis vary with the extent to which an individual statin is dependent for its metabolism on the cytochrome P450 3A4 isoenzyme and the degree to which this isoenzyme's activity is inhibited by a particular antimicrobial. Of note, the interaction between statins and fusidic acid did not feature in seven of eight recent reviews of statin toxicity. Our case report highlights the importance of close monitoring of patients on statins, especially when new drugs are started or if patients become unwell, by checking creatine kinase and liver function tests and by examining for new muscle weakness. Our review of statin-antimicrobial drug interactions suggests that fusidic acid is another CYP450 3A4 enzyme inhibitor with the potential to cause rhabdomyolysis when co-prescribed with simvastatin and atorvastatin.
\end{abstract}

Correspondence to S Teckchandani, Ward 43, Glasgow Royal Infirmary, 1053 Great Western Road, Glasgow GI2 ONR, UK

tel. $+44(0) 7916273061$

e-mail suneetatec@doctors.org.uk

KEYWORDS Antimicrobial, drug interaction, fusidic acid, rhabdomyolysis, statin

DECLARATION OF INTERESTS No conflict of interests declared.

\section{INTRODUCTION}

Hydroxymethyl glutamyl coenzyme A reductase inhibitors (statins) reduce vascular risk and are widely prescribed for patients with, or likely to develop, ischaemic heart disease. These drugs are generally well tolerated' but have two uncommon and potentially serious adverse effects: elevation of liver enzymes, which are usually asymptomatic,' and skeletal muscle disorders. The effects on skeletal muscle range from benign myalgias and myopathy to rhabdomyolysis. Myopathy may be defined by a ten-fold elevation in creatine kinase (CK) with muscle pain or weakness, while rhabdomyolysis is usually associated with $C K>10,000$ international units per litre (IU/I) and acute kidney injury, which may be lifethreatening. ${ }^{1-8}$

The placebo-corrected incidence of rhabdomyolysis in a systematic review of 20 statin trials was $1.6 / 100,000$ per year, ${ }^{9}$ but the incidence is likely to be higher than this in everyday clinical practice when statins are knowingly or inadvertently co-prescribed with drugs that inhibit their metabolism. ${ }^{10} \mathrm{Against}$ this background we wish to report a case of rhabdomyolysis that occurred when fusidic acid was co-prescribed with atorvastatin, potentiating the toxicity of both drugs. We also review the literature on statin-antimicrobial drug interactions.

\section{CASE REPORT}

A 69-year-old male presented with multi-organ failure secondary to left lower lobe consolidation, for which he required ventilation, dialysis and inotropic support. One week previously he had been prescribed flucloxacillin ( $2 \mathrm{~g}$ per day) and fusidic acid ( $2.25 \mathrm{~g}$ per day), following the excision of an infected hip prosthesis. His medical history included myocardial infarction, hypertension and hyperlipidaemia, and his routine medications were ramipril ( $10 \mathrm{mg}$ per day), atenolol (50 mg per day), atorvastatin (40 mg per day), ezetimibe (10 mg per day), aspirin (75 mg per day) and diclofenac (100 mg per day).

We were able to withdraw ventilatory and circulatory support after three days, although the patient remained dialysis-dependent and slow to mobilise. We observed at this point that he could not sit up unaided and demonstrated proximal muscle weakness with CK 21,652 IU/I (normal range 0-195). Liver function tests were also deranged, with bilirubin $60 \mathrm{mmol} / \mathrm{l}$, aspartate aminotransferase (AST) $618 \mathrm{IU} / \mathrm{l}$ (normal range 0-42), alanine aminotransferase (ALT) $177 \mathrm{IU} / \mathrm{l}$ (normal range 0-50), gamma GT $213 \mathrm{IU} / \mathrm{I}$ (normal range $0-50$ ) and alkaline phosphatase $175 \mathrm{IU} / \mathrm{l}$ (normal range 35-130). Atorvastatin, ezetimibe and fusidic acid were stopped. 


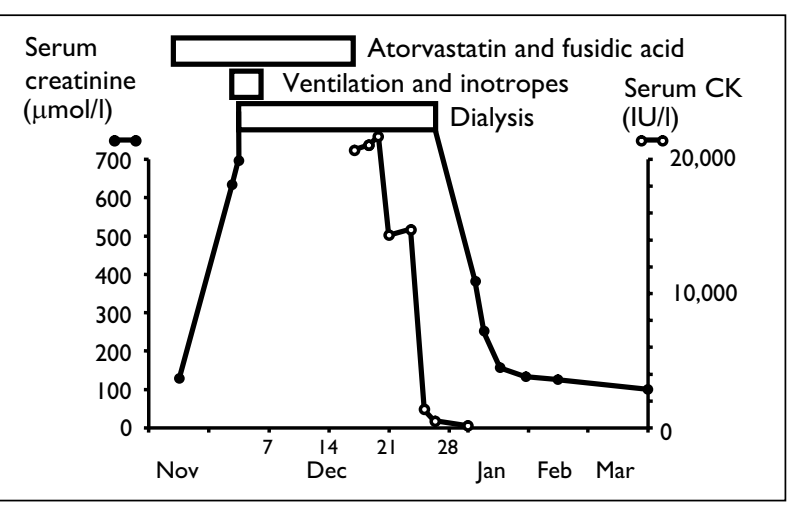

FIGURE I Clinical course of a patient whose acute renal failure was caused initially by pneumonia with multi-organ failure and subsequently by rhabdomyolysis due to an interaction between atorvastatin and fusidic acid.

The patient was unable to walk for a further four days and remained dialysis-dependent for another ten days (Figure I).When reviewed at the clinic two months after his initial presentation, muscle power had returned to normal and serum creatinine was $105 \mu \mathrm{mol} / \mathrm{l}$. We subsequently reported our findings to the Medicines and Healthcare products Regulatory Agency.

\section{DISCUSSION}

\section{Evidence of a statin-fusidic acid interaction}

Our patient's presentation with pneumonia and multiorgan failure may well have led to a delay in the recognition of his rhabdomyolysis, which we did not consider until he complained of muscle weakness after ventilatory and circulatory support were no longer needed. Had severe organ failure caused rhabdomyolysis, we would have expected our patient to present with muscle weakness rather than develop this later in the course of his illness, at a time when his respiratory and circulatory function had recovered.
We also felt that the statin-ezetimibe combination was unlikely to have been responsible: a recent review has suggested that ezetimibe is safe when given in combination with high-dose statins, ${ }^{4}$ and our patient had been on these drugs for several years without untoward effects. We were unaware at the time of his presentation of an interaction between fusidic acid and statins, but subsequently learned that fusidic acid inhibits the CYP3A4 enzyme system and that this particular drug combination is likely to potentiate the toxicities of both drugs. ${ }^{11,12}$ We later found seven case reports of rhabdomyolysis due to a fusidic acid-statin interaction, including four of fusidic acid with atorvastatin ${ }^{13-16}$ and three of fusidic acid with simvastatin. ${ }^{17-19}$ Fusidic acid was the only CYP3A4 inhibitor prescribed in five of these reports. Despite this, the risk of an interaction between statins and fusidic acid is mentioned in only one' of eight recent reviews of statin toxicity. ${ }^{1-8}$

\section{Other statin-antimicrobial interactions}

The statins, the antimicrobials and the cytochrome P450 isoenzymes responsible for their metabolism are shown in Table 1.20-43 Simvastatin is mainly metabolised and atorvastatin partly metabolised by CYP3A4, while fluvastatin is metabolised by CYP2C9 with contributions from CYP2C8 and CYP3A4 (summarised by Bellosta et al.'). Rosuvastatin is not extensively metabolised but has some interaction with CYP2C9 and CYP2CI9 isoenzymes. ${ }^{44}$ It will be apparent from Table I that the risks of rhabdomyolysis may vary both with the statin and with the antimicrobial. Simvastatin $80 \mathrm{mg}$ daily caused more rhabdomyolysis than atorvastatin $80 \mathrm{mg}$ daily in the statin trials that compared more intensive with less intensive treatment (summarised by Armitage ${ }^{5}$ ), and is probably more likely than atorvastatin to cause rhabdomyolysis when given in combination with macrolide antibiotics ${ }^{45}$ and azole antifungals. ${ }^{46,47}$

TABLE I Statins, antimicrobials and risks of rhabdomyolysis

\begin{tabular}{|c|c|c|c|c|c|}
\hline & $\begin{array}{l}\text { Clarithromycin } \\
\text { 3A4 }\end{array}$ & $\begin{array}{l}\text { Erythromycin } \\
\text { 3A4 }\end{array}$ & $\begin{array}{l}\text { Ketoconazole } \\
\text { 3A4 }\end{array}$ & $\begin{array}{l}\text { Fluconazole } \\
2 \mathrm{C} 9,2 \mathrm{C} 19\end{array}$ & $\begin{array}{l}\text { Fusidic acid } \\
\text { 3A4 }\end{array}$ \\
\hline $\begin{array}{l}\text { Pravastatin } \\
\text { Not significantly } \\
\text { metabolised by P450 }\end{array}$ & Caution $^{20}$ & Caution & Should be safe ${ }^{21}$ & Should be safe ${ }^{22}$ & Should be safe \\
\hline $\begin{array}{l}\text { Fluvastatin } \\
\text { Mainly metabolised by } 2 \mathrm{C} 9 \text {, } \\
\text { partly by } 2 \mathrm{C} 8 \text { and } 3 \mathrm{~A} 4\end{array}$ & Should be safe & Should be safe ${ }^{23}$ & Should be safe $e^{23}$ & $\mathrm{Omit}^{22}$ & Should be safe \\
\hline $\begin{array}{l}\text { Simvastatin } \\
\text { Mainly metabolised by } 3 \mathrm{~A} 4\end{array}$ & Omit ${ }^{24-29}$ & Omit $\mathrm{i}^{29,30}$ & Omit ${ }^{31-34}$ & Caution ${ }^{35-37}$ & Omit \\
\hline $\begin{array}{l}\text { Atorvastatin } \\
\text { Partly metabolised by } 3 \mathrm{~A} 4\end{array}$ & $\begin{array}{l}\text { Omit or max } \\
\text { dose } 20 \mathrm{mg}^{20,38,39}\end{array}$ & $\begin{array}{l}\text { Omit or max } \\
\text { dose } 10 \mathrm{mg}^{40}\end{array}$ & $\begin{array}{l}\text { Omit or max } \\
\text { dose } 40 \mathrm{mg}^{41}\end{array}$ & Should be safe & $\begin{array}{l}\text { Omit or max } \\
\text { dose } 10 \mathrm{mg}\end{array}$ \\
\hline $\begin{array}{l}\text { Rosuvastatin } \\
\text { Less than } 10 \% \text { metabolised } \\
\text { by } 2 \mathrm{C} 9 \text { and } 2 \mathrm{Cl} 9\end{array}$ & Should be safe & Should be safe $\mathrm{e}^{42}$ & Should be safe & $\begin{array}{l}\text { Omit or } \max \\
\text { dose } 10 \mathrm{mg}^{43}\end{array}$ & Should be safe \\
\hline
\end{tabular}

"This table shows the cytochrome P450 isoenzymes responsible for the metabolism of statins and inhibited by five commonly used antibiotics. Advice to omit or limit the dose of statin is based on case reports or increase in the area under curve (AUC) likely to arise as a result of cytochrome P450 interaction. 'Caution' means case report or increase in AUC independent of cytochrome P450 enzyme system. 'Should be safe' means no case report found and no interaction anticipated. Superscript references denote the papers providing evidence for the advice given in each box. 
There were no cases of rhabdomyolysis reported with pravastatin in the Prospective Pravastatin Pooling Project, ${ }^{48}$ possibly reflecting the fact that this drug is not metabolised by cytochrome P450. Rhabdomyolysis has nevertheless been reported with pravastatin, ${ }^{49}$ indicating that other mechanisms must be responsible. Saito et al. have suggested that P-glycoproteins and organic anion transporter polypeptides may be responsible for statindrug interactions at a pharmacokinetic level..$^{50}$ There are fewer data on the safety of rosuvastatin, the most potent of the statins and the newest to be licensed for use in the treatment of hyperlipidaemia. Pre- and post-marketing surveillance suggests a myopathy rate similar to that of the other statins, ${ }^{51}$ while head-to-head comparisons of rosuvastatin with atorvastatin in 25 studies of 19,621 patients have shown no significant differences in side effects between $5-40 \mathrm{mg}$ rosuvastatin and $10-80 \mathrm{mg}$ atorvastatin..$^{52}$ Other patient risk factors that may increase the possibility of rhabdomyolysis with statins are advanced age, chronic kidney disease, muscular disorders, endocrine disorders, hepatic impairment, prolonged seizures, debilitated status and severe infections. ${ }^{4}$

\section{REFERENCES}

I Bellosta S, Paoletti R, Corsini A. Safety of statins. Focus on clinical pharmacokinetics and drug interactions. Circulation 2004; 109:50-7. doi:I0.II6I/0I.CIR.0000I3I5I9.I5067.If

2 Pasternak RC, Smith SC, Bairey-Merz CN et al. ACC/AHA/NHLBI clinical advisory on the use and safety of statins. J Am Coll Cardiol 2002; 40:567-72. doi:I0.I0I6/S0735-I097(02)02030-2

3 Rosenson RS. Current overview of statin-induced myopathy. Am J Med 2004; I 16:408-16. doi:I0.1016/j.amjmed.2003.10.033

4 Davidson $\mathrm{MH}$, Robinson JG. Safety of aggressive lipid management. J Am Coll Cardiol 2007; 49:I753-62. doi:I0.1016/j.jacc.2007.0I.067

5 Armitage J. The safety of statins in clinical practice. Lancet 2007; 370:I78I-90. doi:I0.10I6/S0I40-6736(07)607I6-8

6 Harper CR, Jacobson TA. The broad spectrum of statin myopathy: from myalgia to rhabdomyolysis. Curr Opin Lipidol 2007; I8:40I-8. doi:I0.1097/MOL.0b013e32825a6773

7 Radcliffe KA, Campbell WW. Statin myopathy. Curr Neurol Neurosci Rep 2008; 8:66-72. doi:I0.1007/s II910-008-00II-4

8 Sathasivam S, Lecky B. Statin induced myopathy. BMJ 2008; 337:a2286. doi:I0.II36/bmj.a2286

9 Law M, Rudnicka AR. Statin safety: a systematic review. Am J Cardiol 2006; 97:52C-60C. doi:I0.1016/j.amjcard.2005.12.010

10 Molden E, Skovlund E, Braathen P. Risk management of simvastatin or atorvastatin interactions with CYP3A4 inhibitors. Drug Saf 2008; 31:587-96. doi:10.2165/00002018-200831070-00004

II Joint Formulary Committee. British National Formulary. 58th ed. London: British Medical Association and Royal Pharmaceutical Society of Great Britain; 2009.

12 Sodium fusidate: summary of product characteristics. Available from: http://emc.medicines.org.uk

13 Wenisch C, Krause R, Fladerer $\mathrm{P}$ et al. Acute rhabdomyolysis after atorvastatin and fusidic acid therapy. Am J Med 2000; 109:78. doi:I0.10I6/S0002-9343(00)00367-3

I4 Kahri J,Valkonen M, Backlund T et al. Rhabdomyolysis in a patient receiving atorvastatin and fluconazole. Eur J Clin Pharmacol 2005; 60:905-7. doi:10.1007/s00228-004-0858-5

I5 Nwaejike N, Sidhu P. A note to cardiothoracic surgeons: statins can interact with ciprofloxacillin and fusidic acid to cause rhabdomyolysis and myoglobinuric renal failure. Internet J Thorac Cardiovasc Surg 2007: 8(2): letters to the editor.

\section{CONCLUSION}

The increasing tendency to treat older patients to more demanding lipid targets and the fact that statins are frequently co-prescribed with interacting drug ${ }^{53}$ means that the risk of rhabdomyolysis in patients taking statins can only increase. Our case report highlights the importance of close monitoring of patients on statins, especially when new drugs are started or patients become unwell, by checking creatine kinase and liver function tests and by examining for new muscle weakness. Our review of statin-antimicrobial drug interactions suggests that fusidic acid is another CYP450 3A4 enzyme inhibitor with the potential to cause rhabdomyolysis when co-prescribed with simvastatin and atorvastatin.

Acknowledgement We wish to thank Mrs Josephine Campbell for her help with this manuscript.

16 O'Mahony C, Campbell VL, Al-Khayatt MS et al. Rhabdomyolysis with atorvastatin and fusidic acid. Postgrad Med J 2008; 84:325-7. doi:I0.I I36/pgmj.2007.064097

17 Kotanko P, Kirisits W, Skrabal F. Rhabdomyolysis and acute renal graft impairment in a patient treated with simvastatin, tacrolimus and fusidic acid. Nephron 2002; 90:234-5. doi: I 0. I I59/000049053

18 Yuen SL, McGarity B. Rhabdomyolysis secondary to interaction of fusidic acid and simvastatin. Med J Aust 2003; 179:172.

19 Burtenshaw AJ, Sellors G, Downing R. Presumed interaction of fusidic acid with simvastatin. Anaesthesia 2008; 63:656-8. doi:I0.I I I I/j. I365-2044.2007.05434.x

20 Jacobson TA. Comparative pharmacokinetic interaction profiles of pravastatin, simvastatin, and atorvastatin when co-administered with cytochrome P450 inhibitors. Am J Cardiol 2004; 94: II40-6. doi:10.1016/j.amjcard.2004.07.080

21 Jacobsen W, Kirchner G, Hallensleben $K$ et al. Comparison of cytochrome P-450-dependent metabolism and drug interactions of the 3-hydroxy-3-methylglutaryl-CoA reductase inhibitors lovastatin and pravastatin in the liver. Drug Metab Dispos 1999; 27:173-9.

22 Kantola T, Backman JT, Niemi M et al. Effect of fluconazole on plasma fluvastatin and pravastatin concentrations. Eur J Clin Pharmacol 2000; 56:225-9. doi:I0.1007/s002280000I27

23 Scripture CD, Pieper JA. Clinical pharmacokinetics of fluvastatin. Clin Pharmacokinet 200I; 40:263-8I. doi:I0.2165/00003088200।40040-00003

24 Lee AJ, Maddix DS. Rhabdomyolysis secondary to a drug interaction between simvastatin and clarithromycin. Ann Pharmacother 200I; 35:26-3I. doi:10.1345/aph. I0I77

25 Kahri AJ, Valkonen MM, Vuoristo MK et al. Rhabdomyolysis associated with concomitant use of simvastatin and clarithromycin. Ann Pharmacother 2004; 38:719. doi: I0.1345/aph.ID243

26 Valero R, Rodrigo E, Zubimendi JA et al. [Rhabdomyolysis secondary to the interaction of statins with macrolides in a renal transplant patient.] Nefrologia 2004; 24:382-3. In Spanish.

27 Trieu J, Emmett L, Perera C et al. Rhabdomyolysis resulting from interaction of simvastatin and clarithromycin demonstrated by Tc-99m MDP scintigraphy. Clin Nucl Med 2004; 29:803-4. doi:I0.1097/00003072-2004/2000-00008 
S Teckchandani, S Robertson, A Almond et al.

28 Chouhan UM, Chakrabarti S, Millward LJ. Simvastatin interaction with clarithromycin and amiodarone causing myositis. Ann Pharmacother 2005; 39:I760-I. doi:I0.I345/aph.IG I 95

29 Molden E, Andersson KS. Simvastatin-associated rhabdomyolysis after coadministration of macrolide antibiotics in two patients. Pharmacotherapy 2007; 27:603-7. doi:10.1592/phco.27.4.603

30 Kantola T, Kivistö KT, Neuvonen PJ. Erythromycin and verapamil considerably increase serum simvastatin and simvastatin acid concentrations. Clin Pharmacol Ther 1998; 64:177-82. doi:I0.1016/ S0009-9236(98)90I5I-5

3I Gilad R, Lampl Y. Rhabdomyolysis induced by simvastatin and ketoconazole treatment. Clin Neuropharmacol 1999; 22:295-7.

32 Venkatakrishnan K, von Moltke LL, Greenblatt DJ. Effects of the antifungal agents on oxidative drug metabolism: clinical relevance. Clin Pharmacokinet 2000; 38:III-80. doi:I0.2I65/00003088200038020-00002

33 Itakura H, Vaughn D, Haller DG et al. Rhabdomyolysis from cytochrome $\mathrm{p}-450$ interaction of ketoconazole and simvastatin in prostate cancer. J Urol 2003; 169:613. doi:10.1016/S00225347(05)63967-5

34 Akram K, Rao S, Parker M. A lesson for everyone in drug-drug interactions. Int J Cardiol 2007; II8:el9-20. doi:10.1016/j. ijcard.2006.II.235

35 Hazin R, Abuzetun JY, Suker $M$ et al. Rhabdomyolysis induced by simvastatin-fluconazole combination. J Natl Med Assoc 2008; 100:444-6.

36 Moro H, Tsukada H, Tanuma A et al. Rhabdomyolysis after simvastatin therapy in an HIV-infected patient with chronic renal failure. AIDS Patient Care STDS 2004; 18:687-93. doi:10.1089/ apc.2004.18.687

37 Shaukat A, Benekli M, Vladutiu GD et al. Simvastatin-fluconazole causing rhabdomyolysis. Ann Pharmacother 2003; 37:1032-5. doi: 10.1345/aph.IC467

38 Mah Ming JB, Gill MJ. Drug-induced rhabdomyolysis after concomitant use of clarithromycin, atorvastatin and lopinavir/ ritonavir in a patient with HIV. AIDS Patient Care STDS 2003; 17:207-10. doi:I0.1089/108729/0332/655854

39 Sipe BE, Jones RJ, Bokhart GH. Rhabdomyolysis causing AV blockade due to possible atorvastatin, esomeprazole and clarithromycin interaction. Ann Pharmacother 2003; 37:808-1I. doi: 10.1345/aph.IC396

40 Siedlik PH, Olson SC, Yang BB, Stern RH. Erythromycin co-administration increases plasma atorvastatin concentrations. J Clin Pharmacol 1999; 39:501-4.

4I Lipitor: summary of product characteristics. Available from: http://emc. medicines.org.uk
42 Cooper KJ, Martin PD, Dane AL et al. The effects of erythromycin on the pharmacokinetics of rosuvastatin. Eur J Clin Pharmacol 2003; 59:5I-6.

43 Cooper KJ, Martin PD, Dane AL et al. The effect of fluconazole on the pharmacokinetics of rosuvastatin. Eur J Clin Pharmacol 2002; 58:527-31. doi:10.1007/s00228-002-0508-8

44 McTaggart F, Buckett L, Davidson R et al. Preclinical and clinical pharmacology of rosuvastatin, a new 3-hydroxy-3-methylglutaryl coenzyme $\mathrm{A}$ reductase inhibitor. Am J Cardiol 200I; 87:28B-32B. doi:I0.1016/S0002-9149(0I)0I454-0

45 Baxter K, Marshall A, Sharp J. Drug interactions that can occur with statins and macrolide antibacterials. Pharm J 2008; 280:630.

46 Kantola T, Kivistö KT, Neuvonen PJ. Effect of itraconazole on the pharmacokinetics of atorvastatin. Clin Pharmacol Ther 1998; 64:58-65. doi:I0.1016/S0009-9236(98)90023-6

47 Neuvonen PJ, Kantola T, Kivistö KT. Simvastatin but not pravastatin is very susceptible to interaction with the CYP3A4 inhibitor itraconazole. Clin Pharmacol Ther 1998; 63:332-4I. doi:I0.1016/ S0009-9236(98)90165-5

48 Simes J, Furberg CD, Braunwald E et al. for the Prospective Pravastatin Pooling Project Investigators. Effects of pravastatin on mortality in patients with and without coronary heart disease across a broad range of cholesterol levels: the Prospective Pravastatin Pooling Project. Eur Heart J 2002; 23:207-I5. doi:I0.1053/euhj.200I.2775

49 Schindler C, Thoms M, Matschke K et al. Asymptomatic statininduced rhabdomyolysis after long-term therapy with the hydrophilic drug pravastatin. Clin Ther 2007;29: I72-6. doi: I0.1016/j. clinthera.2007.01.017

50 Saito M, Hirata-Koizumi M, Urano T et al. A literature search on pharmacokinetic drug interactions of statins and analysis of how such interactions are reflected in package inserts in Japan. J Clin Pharm Ther 2005; 30:2 I-37. doi:I0. I I II/j. I365-27I0.2004.00605.x

5 I Davidson MH. Rosuvastatin safety: lessons from the FDA review and post-approval surveillance. Expert Op Drug Saf 2004; 3:547-57. doi:I0.15I7/I4740338.3.6.547

52 Wlodarczyk J, Sullivan D, Smith M. Comparison of benefits and risks of rosuvastatin versus atorvastatin from a meta-analysis of head-to-head randomized control trials. Am J Cardiol 2008; 102:1654-62. doi:I0.1016/j.amjcard.2008.08.014

53 Stang P, Morris L, Kempf J et al. The coprescription of contraindicated drugs with statins: continuing potential for increased risk of adverse events. Am J Ther 2007; 14:30-40. doi:10.1097/0I. mjt.0000208875.6I480.c8

\section{MARK YOUR DIARY 50TH ST ANDREW'S DAY FESTIVAL SYMPOSIUM 2-3 December 2010 at the RCPE}

The RCPE held its first St Andrew's Day Festival Symposium in December 1961. This year, the College would like to make the 50th symposium a celebration of medical advances and to include a historical perspective in its flagship event. The theme of acute medicine will still run through the symposium. Please put the date in your diary. Further details will follow in due course. 